\title{
Risk factors for Australian school-age children in socio-economically disadvantaged populations not passing ear and hearing screening
}

\section{Catherine M McMahon ${ }^{a, d}$, Jade McLennan ${ }^{b}$, Neil J Orrb ${ }^{b}$ Kai Nash ${ }^{b}$ and Phillip Nakadc}

a HEAR Centre, Macquarie University, Sydney, NSW, Australia

b Department of Linguistics, Macquarie University, Sydney, NSW, Australia

${ }^{c} \mathrm{MQ}$ Health Speech and Hearing Clinic, Macquarie University, Sydney, NSW, Australia

d Corresponding author: cath.mcmahon@mq.edu.au

\section{Article history}

Publication date: 2 December 2021

Citation: McMahon CM, McLennan J, Orr NJ, Nash K, Nakad P. Risk factors for Australian school-age children in socio-economically disadvantaged populations not passing ear and hearing screening. Public Health Res Pract. 2021;31(5):e3152130. https://doi. org/10.17061/phrp3152130

\section{Key points}

- Understanding the risk of hearing loss in socio-economically disadvantaged children can enable earlier, targeted and more effective care

- A retrospective study of school children from at-risk populations found that higher risks of middle ear dysfunction were associated with younger age and seasonal variation

- Targeted screening programs can identify hearing loss during critical learning years, mitigating longer-term educational, social and mental health outcomes

\section{Abstract}

Objectives and importance of study: The consequences of sensorineural hearing loss in young children include poor speech and language development, poor educational outcomes, and delayed socio-emotional development. For children who face socio-economic disadvantage, middle ear disease is more prevalent, access to primary health care is more difficult, and psychosocial and education supports are limited. Because of this, the consequences may be amplified. Understanding the risks associated with hearing loss and middle ear dysfunction in underserved populations can enable an earlier, more targeted and cost-effective approach to identifying those with hearing loss and effectively connecting them to systems of care.

Study type: Retrospective study.

Method: This study describes the outcomes of an ear and hearing screening program for children from lower socio-economic backgrounds ( $n=2489$; mean age 11.0 years, standard deviation 1.74 years) in New South Wales (NSW), Australia, between 2013 and 2016. Screening was conducted in a quiet room, and the test protocol included otoscopy, $226 \mathrm{Hertz}(\mathrm{Hz})$ tympanometry, and pure tone screening at octave frequencies from $500 \mathrm{~Hz}$ to $4000 \mathrm{~Hz}$ with a referral criterion of 20 decibels hearing level $(\mathrm{dB} \mathrm{HL})$ at any one frequency. Outcomes were categorised into 1) pass; 2) middle ear dysfunction only; and 3) did not pass hearing screen (with or without middle ear dysfunction). Multinomial logistic regression was used to investigate risk factors for hearing loss and middle ear dysfunction. The factors examined were age, gender, socio-educational advantage, quarter of year assessed, non-English speaking background (NESB), Aboriginal status and region.

Results: Higher risks of middle ear dysfunction were associated with younger age and seasonal variation, with higher risk in winter and spring months 
- Stronger partnerships across health and education can support children with hearing loss and those at risk of hearing loss
(July-September and October-December, compared with January-March). There were no differences between those from NESB and those with English as a first language, between the Aboriginal population and non-Aboriginal population, or between those who resided within or outside a major city.

Conclusion: More than one in 10 school-age children from lower socioeconomic backgrounds experience hearing loss (11.5\%). Targeted ear and hearing screening programs offer an opportunity to identify hearing loss during critical learning years and seasons, mitigating longer-term effects on education, and social and mental health.

\section{Introduction}

Throughout a child's early years, undetected hearing loss during the critical period of neurocognitive development can have significant consequences for their speech and language development, educational achievement, and neurocognitive and social-emotional growth. ${ }^{1-3}$

Newborn hearing screening programs can reduce the burden of congenital hearing loss on the individual and society by mitigating many downstream effects. ${ }^{4}$ However, approximately half of childhood hearing loss remains undetected by such programs ${ }^{5}$, either because of the insensitivity of the test in detecting milder forms of hearing loss or because of progressive or infection-related hearing loss. Australian data showing the age of first hearing aid fitting of children with permanent hearing loss (who are eligible for fully subsidised hearing services until the age of 26 years) support this. Two predominant peaks can be seen: 1) within the first year of life, attributed to the success of newborn hearing screening; and 2) a broader peak observed across the early educational years (see Figure 1; data shown for $2020^{6}$ ).

A recent systematic review estimated that 3.4-12.8\% of Australian primary school children have hearing loss of some degree - substantially higher than the rate in other high-income countries ${ }^{7}$; most of which is conductive hearing loss. These figures may be influenced by high rates of otitis media (OM) observed in populations in Australia with limited access to healthcare - including Aboriginal and Torres Strait Islander children (herein referred to as Aboriginal). A retrospective study of ear and hearing screening data conducted between 1998 and 2004 in three primary schools in Western Australia showed that up to $42 \%$ of Aboriginal children living in urban areas had middle ear disease, and $19.1 \%$ of all children exhibited hearing loss ${ }^{8}$, more than double the rate in the non-Indigenous population. ${ }^{9}$ Prevalence risk of middle ear disease and hearing loss typically increases with remoteness. However, a comparative study of 408 urban and 438 regional Aboriginal primary school children (aged 3-15 years) from Western Australia showed evidence of $\mathrm{OM}$ in $30.7 \%$ of the urban cohort and $15.5 \%$ of the regional cohort. ${ }^{10}$ Other studies have shown that up to $91 \%$ of Aboriginal children living in very remote areas have a middle ear abnormality. ${ }^{11}$

The recently launched World Health Organization World Report on Hearing ${ }^{12}$ recommends that all countries implement school screening programs to ensure

Figure 1. Number of Australians with permanent hearing loss aged 0-25 years first fitted with hearing aids, 2020

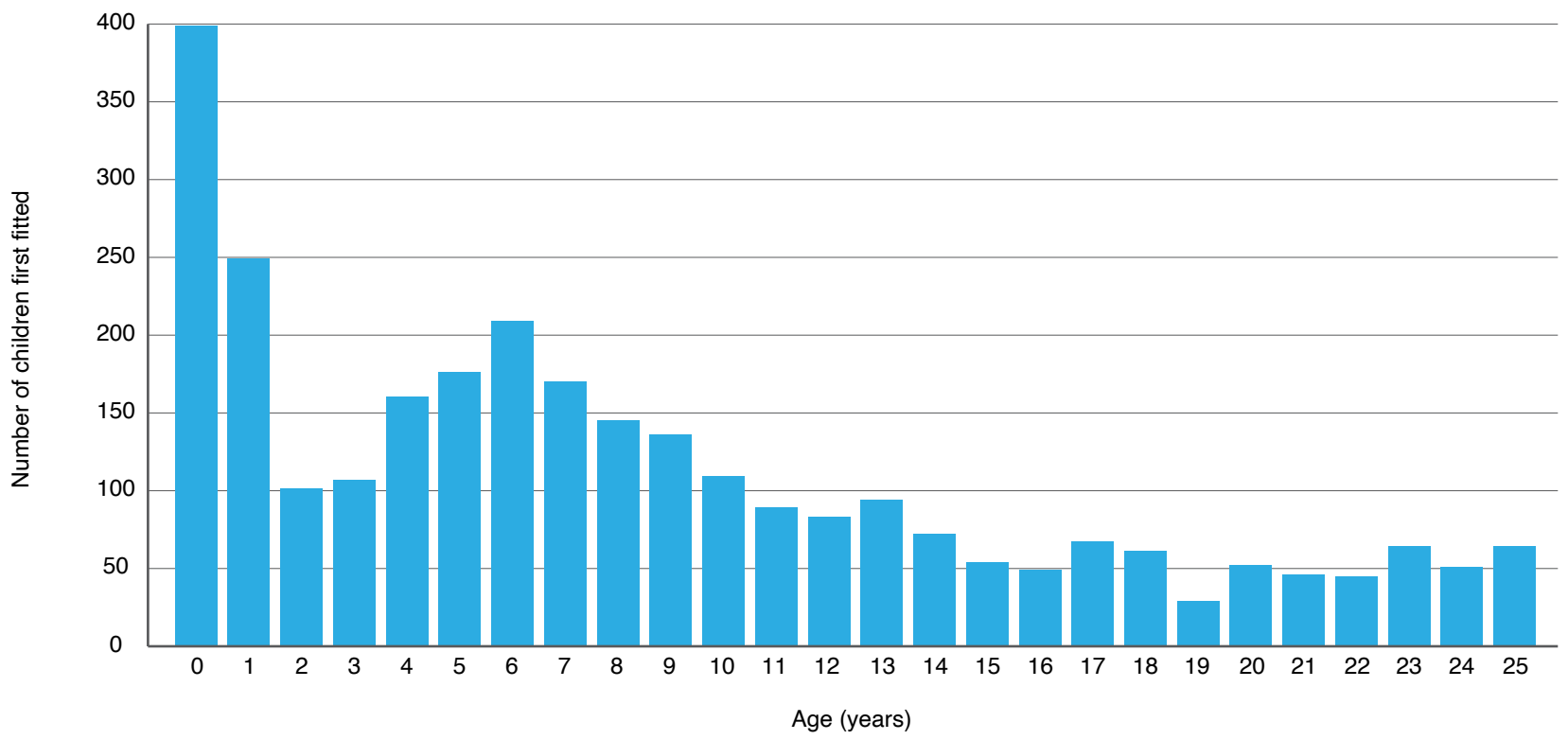


early detection of ear disease and hearing loss. The current absence of these programs can be attributed to the costs associated with administering screening programs and the relative perceived benefit of newborn hearing screening programs already in place in many high-income countries. ${ }^{13,14}$ Universal preschool or school-based hearing screening programs may not be economically viable and may be logistically burdensome in high-income countries such as Australia. ${ }^{15}$ However, targeted screening of populations with lower levels of socio-economic advantage may provide a more costeffective approach to identifying hearing loss and middle ear dysfunction where the risks of these conditions are high. ${ }^{16}$ Certainly, there is an unequal burden of ear disease and hearing loss in children from lower socioeconomic settings. ${ }^{17}$ The combination of increased prevalence and increased cumulative duration of living with middle ear disease is likely to pose significant risks for educational outcomes. For example, Aboriginal children up to 14 years of age experience cumulative middle ear disease for approximately 2 years across their lifetime, compared with approximately 2 months for nonIndigenous children. ${ }^{9}$

Australian Bureau of Statistics data ${ }^{18}$ show that, in 2018, Aboriginal children made up 5.9\% of the total child population (0-14 years) and about 1 in 5 of all children lived in the lowest socio-economic areas (in 2017). Targeted solutions can alleviate the social and economic burden for individuals, their families and society. This retrospective study aimed to determine the risk of middle ear dysfunction, and not passing a hearing screening test, in 2489 school-age children attending a charitybased program providing health and wellbeing services for underserved populations.

\section{Method}

\section{Participants}

The retrospective study included consecutive hearing and middle ear screening data from children who attended a 12-day on-site, away-from-home educational program delivered by a charity-based organisation in a central location in Greater Sydney, New South Wales (NSW), Australia, between January 2013 and December 2016. Children from lower socio-economic backgrounds were selected by their school to participate in the program, which was designed to develop social and emotional skills, build self-esteem and improve overall wellbeing. Children were provided with dental, optical, hearing and medical screening and treatment during their stay. All demographic information was extracted from an electronic database located on-site, and the data are from children who attended hearing screening only once. Demographic information - that is, age, sex, Aboriginal status, non-English speaking background (NESB), ICSEA (a measure of socio-educational advantage) ${ }^{19}$ and quarter of the year in which they were tested - is shown in Table 1.

\section{Referral pathways}

Referrals for health checks were managed centrally by the charity-based organisation to ensure that all results where a child did not pass were integrated into a single referral before they were sent to the child's general practitioner (GP), family and/or other health providers. Referral pathways for hearing and middle ear checks were as follows: 1) children with middle ear dysfunction who did not pass the hearing screen were directly referred to their GP and advised to have a full audiological assessment after medical review of middle ear function; 2) children with normal middle ear function who did not pass the hearing screen were directly referred to Hearing Australia (an Australian Government hearing services agency for people with permanent hearing loss from 0-26 years of age); and 3) children with middle ear dysfunction who passed the hearing screen were provided with a letter to their GP requesting a medical review of middle ear function.

\section{Study design}

Audiometric screenings were administered by postgraduate audiology students under the direct supervision of a professionally accredited audiologist. Screenings were conducted in two quiet rooms within the centre, and noise levels were recorded daily using a sound level meter; levels were consistently lower than the maximum sound pressure levels allowable for background noise in audiometric rooms. A Hiene Mini 3000 Otoscope and an Interacoustics Titan Middle Ear Analyzer Tympanometer were used to conduct otoscopy and tympanometry. An Interacoustics AD629E audiometer and passive attenuating Sennheiser HDA200 headphones were used for audiometry. Results for otoscopy were qualitatively recorded. The normative values used for tympanometry were adapted from Jerger classification guidelines for adults - that is, ear canal volume of $0.5-2 \mathrm{~cm}^{3}$, static compliance $0.2-1.8 \mathrm{~cm}^{3}$ and middle ear pressure $>-150 \mathrm{daPa}$ (decapascals). A screening level of 20 decibels hearing level ( $\mathrm{dB} \mathrm{HL}$ ) was selected for audiometry, and the tested frequencies were 500, 1000, 2000 and 4000 hertz $(\mathrm{Hz})$. Each child was presented with an initial $60 \mathrm{~dB} \mathrm{HL}$ tone followed by a $40 \mathrm{~dB} \mathrm{HL}$ presentation and three consecutive $20 \mathrm{~dB} \mathrm{HL}$ presentations at each frequency in each ear. A pass was defined when the child responded correctly to two of the three presentations at $20 \mathrm{~dB} \mathrm{HL}$ at all tested frequencies, in both ears. If the child failed to respond to the two screening presentations at any frequency, their threshold was determined using the standard HughsonWestlake technique. Children were deemed to have failed screening audiometry if their threshold exceeded $20 \mathrm{~dB} H \mathrm{~L}$ at any frequency, in either ear. 
Table 1. Participant characteristics and outcomes $(N=2489)$

\begin{tabular}{|c|c|c|c|c|}
\hline Characteristic & $\begin{array}{l}\text { Pass } \\
n(\%)\end{array}$ & $\begin{array}{c}\text { Risk of hearing loss } \\
n(\%)\end{array}$ & $\begin{array}{c}\text { Middle ear dysfunction } \\
n(\%)\end{array}$ & Total \\
\hline \multicolumn{5}{|l|}{ Age (years) } \\
\hline $5-9$ & $384(56.2)$ & $84(12.3)$ & $215(31.5)$ & 683 \\
\hline $10-14$ & $1077(60.8)$ & $197(11.1)$ & $497(28.1)$ & 1771 \\
\hline $15-18$ & $24(68.6)$ & $4(11.4)$ & $7(20.0)$ & 35 \\
\hline Total & $1485(59.7)$ & $285(11.5)$ & $719(28.9)$ & 2489 \\
\hline \multicolumn{5}{|l|}{ Sex } \\
\hline Male & $711(59.2)$ & $137(11.4)$ & $353(29.4)$ & 1201 \\
\hline Female & $773(60.1)$ & $148(11.5)$ & $366(28.4)$ & 1287 \\
\hline Total & 1484 & 285 & 719 & 2488 \\
\hline Missing & 1 & & & 1 \\
\hline \multicolumn{5}{|l|}{ ICSEA (25th percentiles) } \\
\hline 1 (1007-1193) (highest) & $306(57.7)$ & $66(12.5)$ & $158(29.8)$ & 530 \\
\hline 2 (958-1006) & $322(59.9)$ & $59(11.0)$ & $157(29.2)$ & 538 \\
\hline $3(910-957)$ & $326(62.0)$ & $57(10.8)$ & $143(27.2)$ & 526 \\
\hline 4 (582-909) (lowest) & $324(59.1)$ & $56(10.2)$ & $168(30.7)$ & 548 \\
\hline Total & 1278 & 238 & 626 & 2142 \\
\hline Missing & 207 & 47 & 93 & 347 \\
\hline \multicolumn{5}{|c|}{ Aboriginal and Torres Strait Islander } \\
\hline Yes & $394(57.9)$ & $83(12.2)$ & 203 (29.9) & 680 \\
\hline No & $1091(60.3)$ & $202(11.2)$ & $516(28.5)$ & 1809 \\
\hline Total & 1485 & 285 & 719 & 2489 \\
\hline \multicolumn{5}{|c|}{ Non-English speaking background } \\
\hline Yes & $142(63.1)$ & $24(10.7)$ & $59(26.2)$ & 225 \\
\hline No & $1343(59.3)$ & $261(11.5)$ & $660(29.2)$ & 2264 \\
\hline Total & 1485 & 285 & 719 & 2489 \\
\hline \multicolumn{5}{|l|}{ Region } \\
\hline Major city & $838(58.1)$ & $170(11.8)$ & $435(30.1)$ & 1443 \\
\hline Outside major city & $645(61.8)$ & $115(11.0)$ & $284(27.2)$ & 1044 \\
\hline Total & 1483 & 285 & 719 & 2487 \\
\hline Missing & 2 & & & 2 \\
\hline \multicolumn{5}{|l|}{ Time tested } \\
\hline Jan-Mar & $251(64.0)$ & $40(10.2)$ & $101(25.8)$ & 392 \\
\hline Apr-Jun & $419(62.0)$ & $74(10.9)$ & $183(27.1)$ & 676 \\
\hline Jul-Sep & $509(57.2)$ & $104(11.7)$ & $277(31.1)$ & 890 \\
\hline Oct-Dec & $306(57.6)$ & $67(12.6)$ & $158(29.8)$ & 531 \\
\hline Total & 1485 & 285 & 719 & 2489 \\
\hline Total & $1485(59.7)$ & $285(11.5)$ & $719(28.9)$ & 2489 \\
\hline
\end{tabular}

ICSEA = Index of Community Socio-Educational Advantage ${ }^{19}$ 


\section{Statistical analysis}

Frequencies, means and proportions were calculated to ascertain the characteristics of the study sample. Multinomial logistic regression was used to investigate risk factors for two ear conditions: hearing loss and middle ear disease. One outcome variable with three levels was used in the analysis. The levels were 'passed' and hearing loss or middle ear dysfunction, with 'passed' being the reference category. The predictor variables were entered in one step, with continuous variables entered as factors and categorical variables as covariates. Odds ratios (ORs), 95\% confidence intervals and $p$ values were calculated for each predictor variable. All statistical tests were two tailed, with alpha $=0.05$. Statistical analyses were performed using IBM SPSS Version 26 (IBM Corporation, Armonk, New York).

\section{Ethics approval}

Parental consent was obtained for all children to complete hearing screening as part of a general health check. Because of the retrospective analysis, direct parental consent for children to participate in this study was waived, and the project was approved by the Macquarie University Human Research Ethics Committee (\#5201700248).

\section{Results}

Participants comprised 2489 children (51.7\% female) aged 5.5-17.4 years (mean age 11.0 years, standard deviation [SD] 1.74). Of these, 27.3\% identified as Aboriginal, and $9 \%$ were from NESB. When reported, participants were generally from below-average socioeducational advantage schools (there were 347 missing values). Median ICSEA value was 957.0 (SD 81.9); 50\% of the schools that children attended had ICSEA values in the range 528-957. ICSEA values are calculated on a scale that has a median of 1000 and an SD of 100 . ICSEA values typically range from approximately 500 (representing extremely educationally disadvantaged backgrounds) to about 1300 (representing schools with students with very educationally advantaged backgrounds). ${ }^{19}$ Approximately $58 \%$ of children were from a major city. Similar numbers of children were tested during three of the quarters of the year; a higher proportion was tested between July and September (35.8\%).

Of the 2489 children tested, more than 40\% $(n=1004)$ did not pass the hearing screening assessment. Participants were grouped into three subcategories based on their results: 1) pass; 2) did not pass hearing screen with or without middle ear dysfunction; and 3) current middle ear dysfunction alone. Overall, 285 children (11.5\%) did not pass the hearing screen, and 719 (28.9\%) presented with middle ear dysfunction alone. In the multinomial logistic regression model
(Table 2), significant seasonal differences were found between the July-September quarter and January-March quarter for the likelihood of failing hearing screening when tested (OR 1.96, $1 \mathrm{df}$; 95\% confidence interval [Cl] 1.17, 3.4; $p=0.02)$, and between the October-December and January-March quarters (OR 2.08, 1 df; 95\% Cl 1.16, 3.7; $p=0.01)$. Significant seasonal differences were also found in the likelihood of being diagnosed with middle ear dysfunction in July-September compared with in January-March (OR 1.49, 1 df; 95\% Cl 1.05, 2.1; $p=0.02$ ). Further, children with middle ear dysfunction were younger (around 0.9 years) than those who passed the hearing test (age in years: OR 0.91, 1 df; 95\% Cl 0.85, $0.96 ; p=0.001$ ). Multicollinearity was tested for, and no multicollinear relationships were found in independent variable pairs.

No significant differences were found in either middle ear dysfunction or not passing the hearing screen for those living within or outside major cities, identifying as Aboriginal, from NESB, for school ICSEA value, or for sex for either middle ear dysfunction or hearing loss.

\section{Discussion}

To better understand the factors associated with risk of failing an ear and hearing screening program, we assessed 2489 children as part of an integrated health check for children from underserved populations. The results suggest that middle ear dysfunction is more likely to occur in younger children and that there is seasonal variation, with a higher risk of failing hearing screening and having middle ear dysfunction in the later quarters of the year (July-September [winter-spring] and OctoberDecember [spring-summer]). This has implications for targeting resources for ear and hearing screening to maximise opportunities to address ear disease and hearing loss as soon as possible, particularly in populations with lower socio-economic advantage.

Although relatively few studies have assessed outcomes of school ear and hearing screening programs in Australia compared with other high-income countries, results of the current study are in line with three other Australian studies (discussed in a systematic review). ${ }^{7}$ Minor differences between the studies in the pass/ fail rates of hearing screening (with $11.5 \%$ not passing the hearing screen in the current study) are likely to be attributable to differing screening test levels, with failure rates decreasing with an increase in threshold levels ( $\mathrm{dB} H \mathrm{H}$ ) used to define the pass/fail criteria for referral for hearing loss. Similarly, differences in rates of middle ear dysfunction between the current study (28.9\%) and those conducted previously in Australia (17.9\% ${ }^{20}$ and $18.5 \%{ }^{21}$ ) are the result of different normative values for middle ear pressure. It is difficult to compare estimates of the prevalence of hearing loss in school-age children because test protocols, diagnostic criteria, and age range 
Table 2. Multinomial logistic regression model predicting hearing test outcomes ${ }^{a}$

\begin{tabular}{|c|c|c|c|c|}
\hline Outcome $^{b}$ & Variables in model & Odds ratio & $95 \% \mathrm{Cl}$ & $p$ value \\
\hline \multirow[t]{17}{*}{ Hearing test not passed } & Age (in years) & 0.94 & $0.87,1.023$ & 0.15 \\
\hline & ICSEA $^{19}$ & 1.001 & $0.99,1.003$ & 0.45 \\
\hline & Time of year of test & & & \\
\hline & - January-March & Ref & & \\
\hline & - April-June & $1.59,1 \mathrm{df}$ & $0.88,2.9$ & 0.13 \\
\hline & - July-September & $1.96,1 \mathrm{df}$ & $1.17,3.43$ & 0.02 \\
\hline & - October-December & $2.08,1 \mathrm{df}$ & $1.16,3.7$ & 0.01 \\
\hline & Male & Ref & & \\
\hline & Female & $0.89,1 \mathrm{df}$ & $0.67,1.2$ & 0.39 \\
\hline & Aboriginal and Torres Strait Islander & Ref & & \\
\hline & Non-Aboriginal and Torres Strait Islander & $0.99,1 \mathrm{df}$ & $0.72,1.37$ & 0.95 \\
\hline & Place of residence & & & \\
\hline & - Outside major city & Ref & & \\
\hline & - Major city & $1.009,1 \mathrm{df}$ & $0.73,1.39$ & 0.96 \\
\hline & NESB & & & \\
\hline & - Yes & Ref & & \\
\hline & $-\mathrm{No}$ & $0.84,1 \mathrm{df}$ & $0.51,1.38$ & 0.49 \\
\hline \multirow[t]{17}{*}{ Middle ear dysfunction } & Age (in years) & $0.91,1 \mathrm{df}$ & $0.85,0.96$ & 0.001 \\
\hline & ICSEA & $1.0,1 \mathrm{df}$ & $0.99,1.001$ & 0.29 \\
\hline & Time of year of test & & & \\
\hline & - January-March & Ref & & \\
\hline & - April-June & $1.25,1 \mathrm{df}$ & $0.86,1.81$ & 0.25 \\
\hline & - July-September & $1.49,1 \mathrm{df}$ & $1.05,2.12$ & 0.02 \\
\hline & - October-December & $1.41,1 \mathrm{df}$ & $0.98,2.04$ & 0.06 \\
\hline & Male & Ref & & \\
\hline & Female & $0.91,1 \mathrm{df}$ & $0.75,1.1$ & 0.31 \\
\hline & Aboriginal and Torres Strait Islander & Ref & & \\
\hline & Non-Aboriginal and Torres Strait Islander & $1.03,1 \mathrm{df}$ & $0.83,1.3$ & 0.77 \\
\hline & Place of residence & & & \\
\hline & - Outside major city & Ref & & \\
\hline & - Major city & $1.15,1 \mathrm{df}$ & $0.91,1.43$ & 0.24 \\
\hline & NESB & & & \\
\hline & - Yes & Ref & & \\
\hline & - No & $0.76,1 \mathrm{df}$ & $0.54,1.07$ & 0.12 \\
\hline
\end{tabular}

$\mathrm{Cl}$ = confidence interval; ICSEA = Index of Community Socio-Educational Advantage; NESB = non-English-speaking background; Ref = reference group

a The overall model was statistically significant, indicating that the model predicted the outcome better than chance $\left(\chi^{2}=32.96,18 \mathrm{df}\right.$; $p=0.017)$.

b Reference group for model is 'passed test' (i.e. not referred for hearing loss or middle ear disease). 
of those tested vary across studies; however, similar estimates have been observed elsewhere. For example, cross-sectional population-based findings from the 2012-2013 Canadian Health Measures Survey $(n=2434$ after exclusions; age range 6-19 years) showed that $7.7 \%$ had any hearing loss. ${ }^{22} \mathrm{~A}$ systematic review of children (age range 3-19 years) with hearing loss $>25 \mathrm{~dB} \mathrm{HL}$ from the US showed that the average prevalence of any hearing loss was 3.1\%, ranging from $1.7 \%$ to $5.5 \%{ }^{23}$, with increasing prevalence for lower-income households. A cross-sectional survey of primary school students in Zimbabwe (age unspecified) with screening thresholds of $>30 \mathrm{~dB} H \mathrm{HL}$ showed a prevalence rate of $2.4 \%(95 \%$

$\mathrm{Cl} 2.0,2.8)$, with sensorineural hearing loss found in $1.0 \%$ of children. ${ }^{24}$

In this study, age was a significant predictor for the middle ear dysfunction group; lower rates of middle ear dysfunction were seen with increasing age, consistent with previous studies. ${ }^{17,22}$ This may be a function of the downwards shift in the orientation of the eustachian tube with age, which increases the efficiency of drainage of the middle ear. For example, a study conducted in Iran compared conductive hearing loss rates in school children in grades $1-5$, and the results revealed a decrease in rates with an increase in grade level. ${ }^{25}$ On the other hand, in the current study, age was not a predictor for hearing loss. A similar finding was demonstrated in a population of school-age children in the Solomon Islands ${ }^{26}$, although other studies have found an association between younger age and hearing loss. ${ }^{5,27}$

Seasonal differences in middle ear disease are consistent with previous studies, which have revealed higher rates of middle ear dysfunction in winter and spring months. ${ }^{27}$ Higher rates of $\mathrm{OM}$ have been identified in winter because of the association with colds and other respiratory infections, and higher rates of OM, abnormal middle ear pressure and eustachian tube dysfunction have been identified in spring because of the increase in hayfever and pneumonia cases. ${ }^{28}$ It is important to note that there was no difference in risk between those who self-identified as Aboriginal and non-Aboriginal children. The risk of middle ear disease is associated with social determinants of health, and is therefore higher in Indigenous children, refugees, children in remote areas and those in low-income countries. ${ }^{15,17}$ Within Australia, region (major city versus elsewhere) was not identified as a predictor for either hearing loss or middle ear dysfunction. However, the assessment of remoteness was broadly categorised and based on schools' locations rather than the location of the children's homes, which is a limitation of the current study. Further limitations include the lack of information about other exposure factors for children, such as exposure to cigarette smoke and overcrowding that may be associated with higher rates of middle ear disease and hearing loss. ${ }^{29}$ Although ICSEA data was missing for 347 of 2489 participants, the very tight confidence intervals suggests that this would probably not significantly affect the outcomes.

\section{Conclusions}

$\mathrm{OM}$ and hearing loss are more prevalent in populations with lower levels of social and economic advantage, including those living in rural or remote areas, First Nations populations, and low-income households. ${ }^{17}$ Even mild hearing loss, often not detected by parents but the most common hearing loss resulting from $\mathrm{OM}^{30}$, is associated with educational risk. ${ }^{31}$ Coupled with other risks of poorer educational outcomes in these populations, OM increases the likelihood of reduced early educational outcomes. ${ }^{32}$ The impact of the coronavirus disease 2019 (COVID-19) pandemic in disrupting classroom learning may widen the gap in the future.

School hearing screening programs can effectively identify those with middle ear disease and hearing loss early, although the cost-effectiveness of rolling out such programs across a population remains debated and poorly understood. ${ }^{33}$ Nonetheless, targeting opportunities for middle ear and hearing screening based on the increased educational risks of an individual, or a population attending a school in an area at increased risk of educational disadvantage, could reduce the costs of implementing screening programs. Programs could be provided for children in the early years of schooling ( $<5$ years of age), such as preschool or the beginning of primary school. Targeted screening programs could be further improved by giving teachers information about how to detect a child at risk and when the risk of middle ear disease and hearing loss is greatest, enabling greater opportunities for putting in place surveillance and educational supports.

For screening or surveillance programs to be effective, a robust pathway to care must exist so that children who are detected with ear and hearing problems have an accessible pathway to treatment and the necessary support. Strengthened partnerships across health and education are important to support a child with hearing loss or at risk of hearing loss from middle ear disease. Schools can optimise a child's access to learning with cost-effective supports, including priority seating at the front of the classroom, behavioural management strategies to reduce classroom noise, and classroom amplification systems. Scaffolding childhood development in the early years provides significant benefits to the individual, the family and society.

\section{Peer review and provenance}

Externally peer reviewed, invited. CMM is a Guest Editor of this themed issue of Public Health Research \& Practice. She had no part in the peer-review process for this paper.

\section{Competing interests}

None declared. 


\section{Author contributions}

$\mathrm{CM}$ was responsible for the drafting, analysis of data, writing and editing of the manuscript. JM was responsible for the design, drafting, preliminary analysis of data, writing and editing of the manuscript. NO was responsible for overseeing the data analysis and preliminary analysis of the data. KN was responsible for undertaking a comprehensive literature search, reviewing and editing the manuscript. PN was responsible for the design, overseeing the collection of data, providing analytical advice, reviewing and editing the manuscript.

\section{References}

1. Carney AE, Moeller MP. Treatment efficacy: hearing loss in children. J Speech Lang Hear Res. 1998;41(1):S61-84.

2. Celesia G, Hickok G. Neurocognitive development in congenitally deaf children. In: Aminoff MJ, Boller $F$, Swaab DF (eds). The human auditory system: fundamental organization and clinical disorders. London: Elsevier; 2015:335.

3. Kennedy CR, McCann DC, Campbell MJ, Law CM, Mullee M, Petrou S, et al. Language ability after early detection of permanent childhood hearing impairment. N Eng J Med. 2006;354(20):2131-41.

4. Wake M, Ching TY, Wirth K, Poulakis Z, Mensah FK, Gold L, et al. Population outcomes of three approaches to detection of congenital hearing loss. Pediatrics. 2016;137(1).

5. Fortnum HM, Davis A, Summerfield AQ, Marshall DH, Davis AC, Bamford JM, et al. Prevalence of permanent childhood hearing impairment in the United Kingdom and implications for universal neonatal hearing screening: questionnaire-based ascertainment study. BMJ. 2001;323(7312):536.

6. Hearing Australia. Demographic details of young Australians aged less than 26 years with a hearing loss, who have been fitted with a hearing aid or cochlear implant at 31 December 2020. Sydney: Hearing Australia; 2020 [cited 2021 Oct 22]. Available from: www.hearing. com.au/HearingAustralia/media/assets/Documents/2020Demographics-of-Aided-Young-Australians-at-31December-2020.pdf

7. Choi SMR, Kei J, Wilson WJ. Rates of hearing loss in primary school children in Australia: a systematic review. Speech Lang Hear. 2017;20(3):154-62.

8. Williams CJ, Coates HL, Pascoe EM, Axford Y, Nannup I. Middle ear disease in Aboriginal children in Perth: analysis of hearing screening data, 1998-2004. Med J Aust. 2009;190(10):598-600.

9. McPherson B, Knox E. Hearing loss in urban Aboriginal and Torres Strait Islander schoolchildren. Australian Aboriginal Studies. 1992(2):60-70.
10. Timms L, Grauaug S, Williams C. Middle ear disease and hearing loss in school-aged Indigenous Western Australian children. Asia Pacific Journal of Speech Language and Hearing. 2012 Dec 1;15(4):277-90.

11. Couzos S, Metcalf S, Murray RB. Systematic review of existing evidence and primary care guidelines on the management of otitis media in Aboriginal and Torres Strait Islander populations. Canberra: Australian Government Department of Health and Aged Care; 2001 [cited 2021 Oct 27]. Available from: researchonline.jcu.edu.au/37363/

12. World Health Organisation. World report on hearing. Geneva: Switzerland; 2021 [cited 2021 Oct 27] Available from: www.who.int/publications/i/item/world-report-onhearing

13. Ross DS, Holstrum WJ, Gaffney M, Green D, Oyler RF, Gravel JS. Hearing screening and diagnostic evaluation of children with unilateral and mild bilateral hearing loss. Trends Amplif. 2008;12(1):27-34.

14. Wang C, Bovaird S, Ford-Jones EL, Bender R, Parsonage C, Yau M, et al. Vision and hearing screening in school settings: reducing barriers to children's achievement. Paediatr Child Health. 2011;16(5):271-2.

15. Molloy C, Wake M, Poulakis Z, Barker M, Goldfeld S. Models for screening and surveillance of hearing in early childhood: Identification and review of evidence and efficiency. Sydney: NSW Government; 2014 [cited 2021 Jul 17]. Available from: www.health.nsw.gov.au/ kidsfamilies/MCFhealth/Documents/models-for-screeningand-surveillance.pdf

16. Karunanayake CP, Albritton W, Rennie DC, Lawson JA, McCallum L, Gardipy PJ, et al. Ear infection and its associated risk factors in first nations and rural schoolage Canadian children. Int J Pediatr. 2016;2016:1523897.

17. Leach AJ, Homøe P, Chidziva C, Gunasekera H, Kong K, Bhutta MF, et al. Panel 6: otitis media and associated hearing loss among disadvantaged populations and low to middle- income countries. Int J Pediatr Otorhinolaryngol. 2020;130:109857.

18. Australian Institute of Health and Welfare. Australia's children. Canberra; AlHW; 2018 [last updated 2020 Apr 3] [cited $2021 \mathrm{Nov} 15$ ]. Available from: www.aihw.gov. au/reports/children-youth/australias-children/contents/ background/australian-children-and-their-families

19. Australian Curriculum Assessment and Reporting Authority. Guide to understanding ICSEA. Sydney: ACARA 2013 [cited 2021 Oct 22]. Available from: docs. acara.edu.au/resources/Guide_to_understanding_2013_ ICSEA_values.pdf

20. Driscoll C, Kei J, McPherson B. Outcomes of transient evoked otoacoustic emission testing in 6-year-old school children: a comparison with pure tone screening and tympanometry. Int J Pediatr Otorhinolaryngol. 2001;57(1):67-76.

21. Keogh T, Kei J, Driscoll C, Khan A. Children with minimal conductive hearing impairment: speech comprehension in noise. Audiol Neurootol. 2010;15(1):27-35. 
22. Feder KP, Michaud D, McNamee J, Fitzpatrick E, Ramage-Morin P, Beauregard Y. Prevalence of hearing loss among a representative sample of Canadian children and adolescents, 3 to 19 years of age. Ear Hear. 2017;38(1):7.

23. Mehra S, Eavey RD, Keamy Jr DG. The epidemiology of hearing impairment in the United States: newborns, children, and adolescents. Otolaryngol Head Neck Surg. 2009;140(4):461-72.

24. Westerberg BD, Skowronski DM, Stewart IF, Stewart L, Bernauer M, Mudarikwa L. Prevalence of hearing loss in primary school children in Zimbabwe. Int J Pediatr Otorhinolaryngol. 2005;69(4):517-25.

25. Absalan A, Pirasteh I, Dashti Khavidaki GA, Nasr Esfahani AA, Nilforoush $\mathrm{MH}$. A prevalence study of hearing loss among primary school children in the south east of Iran. Int J Otolaryngol. 2013;2013:138935.

26. Kaspar A, Newton O, Kei J, Driscoll C, Swanepoel DW, Goulios H. Prevalence of ear disease and associated hearing loss among primary school students in the Solomon Islands: otitis media still a major public health issue. Int J Pediatr Otorhinolaryngol. 2018;113:223-8.

27. Van Naarden Braun K, Christensen D, Doernberg N, Schieve L, Rice C, Wiggins L, et al. Trends in the prevalence of autism spectrum disorder, cerebral palsy, hearing loss, intellectual disability, and vision impairment, metropolitan Atlanta, 1991-2010. PloS One. 2015;10(4):e0124120.
28. Winther B, Hayden FG, Owen Hendley J. Middle ear pressure in preschool age children: influence of respiratory illness, season, and picornavirus or bacteria in the nasopharynx. Acta Otolaryngol. 2007;127(8):796-800.

29. DeLacy J, Dune T, Macdonald JJ. The social determinants of otitis media in Aboriginal children in Australia: are we addressing the primary causes? A systematic content review. BMC Public Health. 2020:20(1):492.

30. Cai T, McPherson B. Hearing loss in children with otitis media with effusion: a systematic review. Int J Audiol. 2017 Feb 1;56(2):65-76.

31. Elbeltagy R. Prevalence of mild hearing loss in schoolchildren and its association with their school performance. Int Arch Otorhinolaryngol. 2020;24:e93-e8.

32. Su J-Y, Guthridge S, He VY, Howard D, Leach AJ. The impact of hearing impairment on early academic achievement in Aboriginal children living in remote Australia: a data linkage study. BMC Public Health. 2020;20(1):1-13.

33. Yong M, Liang J, Ballreich J, Lea J, Westerberg BD, Emmett SD. Cost-effectiveness of school hearing screening programs: a scoping review. Otolaryngol Head Neck Surg. 2020;162(6):826-38.

\section{Copyright: (c) (i) (2) (2)}

(c) 2021 McMahon et al. This article is licensed under the Creative Commons Attribution-NonCommercial-ShareAlike 4.0 International Licence, which allows others to redistribute, adapt and share this work non-commercially provided they attribute the work and any adapted version of it is distributed under the same Creative Commons licence terms. See: www.creativecommons.org/licenses/by-nc-sa/4.0/ 